\title{
Barriers to the Right to Health Among Patients of a Public Emergency Department After Implementation of the Affordable Care Act
}

\author{
Shamsher Samra, Elizabeth Pelayo, Mark Richman, ${ }^{* \S}$ Maureen McCollough, and Breena R. Taira
}

\begin{abstract}
Purpose: Emergency physicians are witnesses to the impact of socioeconomic determinants of health on physical and psychiatric illness. Understanding structural barriers to the right to health (RTH) serves as a foundation for interventions to promote health equity. This study was performed to determine self-described barriers to fulfillment of the RTH among a public emergency department (ED) patient population.

Methods: A convenience sample survey between June and August 2014 of 200 patients in public ED assessing demographic characteristics and desired assistance with 36 barriers to fulfillment of the RTH.

Results: There was a high demand for specialty care $(91 \%, 182 / 200)$, access to primary care $(87.5 \%, 175 / 200)$, and access to health insurance $(86 \%, 172 / 200)$. Undocumented residents were significantly more likely to cite health insurance as the most important area for assistance $(p=0.04)$.

Conclusion: Despite implementation of Affordable Care Act, access to health care and insurance were still perceived as the most important barriers among underserved patient populations, particularly undocumented groups.
\end{abstract}

Keywords: ACA; Affordable Care Act; health care disparities; immigrant; insurance; right to health

\section{Introduction}

Signed into law March 30, 2013, The Patient Protection and Affordable Care Act (ACA) sought to improve access to, financial coverage of, and quality of health care by decreasing the number of uninsured Americans through the expansion of public and private health insurance, while decreased health care costs. The ACA was anticipated to reduce the number of uninsured Americans by 30 million by 2016, marking one of the largest expansions of health insurance in the United States history, through a combination of an individual mandate to have health insurance, expansion of Medicaid to legal residents $<138 \%$ of the federal poverty level (FPL), and subsidies to participate in health insurance exchanges for those between $100 \%$ and $400 \%$ of the FPL. ${ }^{1}$

By June 2015, the estimated number of uninsured Americans had decreased by 16.9 million. $^{2}$ Of note, large segments of the populations fall outside the purview the ACA, including those that are explicitly excluded, such as the undocumented or incarcerated, and those that qualify for exemptions to the mandate. ${ }^{3}$

Despite this expansion of health care insurance, barriers to health insurance, health care, and health, even among those not explicitly excluded from the law, remain. ${ }^{4}$ These persistent barriers to health, despite

Department of Emergency Medicine, Olive View-UCLA Medical Center, Sylmar, California.

Present address: Department of Emergency Medicine, Harbor-UCLA Medical Center, Torrance, California.

"Present address: Department of Pediatrics, Kaiser Permanente Southern California, Los Angeles, California.

${ }^{\S}$ Present address: Department of Emergency Medicine, Northwell Health Long Island Jewish Medical Center, New Hyde Park, New York.

*Address correspondence to: Mark Richman, MD, MPH, Department of Emergency Medicine, Northwell Health Long Island Jewish Medical Center, 270-05 76th Avenue, New Hyde Park, NY 11040, E-mail: mrichman1@northwell.edu

(C) Shamsher Samra et al. 2019; Published by Mary Ann Liebert, Inc. This Open Access article is distributed under the terms of the Creative Commons License (http://creativecommons.org/licenses/by/4.0), which permits unrestricted use, distribution, and reproduction in any medium, provided the original work is properly cited. 
normative advances in health care access, not only suggest incomplete implementation of the ACA, but also persistent social and structural barriers to health. In 1976, Thomas McKeown put forth the thesis that health care, and even public health, contributed little to the advances in life expectancy in the 19th and 20th centuries, it instead attributing gains to improvements in quality of life and nutrition. Although the interpretation remains controversial, the idea that there are powerful social determinants of health such as social class, employment status, education, and stress has become mainstream. ${ }^{5}$

For emergency physicians, the relationship between patients' health outcomes and forces that extend beyond the walls of hospitals, outpatient clinics, and the emergency department (ED) is obvious. Emergency physicians are arguably among those most proximate to the acute health manifestations of the chronic structural barriers of poverty, illiteracy, homelessness, and political disenfranchisement. This proximity, combined with the unique role of EDs as "the only component of the entire social welfare system that is protected by law for many of the most disadvantaged" makes it a unique space both to understand and address barriers to health. ${ }^{6}$

The purpose of this study was to evaluate barriers to health among patients presenting to an urban ED. We intentionally use health and human rights language as a normative framework that defines health as "complete physical, mental and social well-being and not merely the absence of disease or infirmity." of health is wedded to the human rights perspective that every individual is entitled to the "the highest attainable standard of physical and mental health," which necessitates access to health care, not simply health insurance. The framework further recognizes the importance of equity and the impact of social and economic conditions on individual health. ${ }^{9}$

Alternative frameworks, such as "patients' rights" or "consumer rights," fail to encompass the full range of rights that derive from inherent human dignity. ${ }^{10}$ "Patients' rights" are limited to the interaction between a patient and the health system and include rights to privacy/confidentiality, quality, autonomy, and informed consent. "Consumer rights" derive from the transactional relationship between the patient and the health system and are similar to contractual rights. Because determinants of health include "social determinants" beyond what occurs in the context of the patient-health system interaction, patients' or consumer rights do not address the full scope of the right to health (RTH). This study aims to identify self-reported barriers (including housing, food security, and personal safety) to health among a safety-net ED population shortly after implementation of the ACA. Consequently, the more expansive "right to health" lens was utilized.

\section{Methods}

Design

This study utilized a voluntary, anonymous questionnaire. All interviews were conducted within the ED between June and August 2014, $\sim 2$ months after the March 31, 2014 registration deadline for the ACA initial enrollment period. All interviews were conducted during daytime hours between $8 \mathrm{AM}$ and $5 \mathrm{PM}$.

\section{Setting}

All interviews were conducted within the ED of the primary safety-net hospital in Northern Los Angeles County. The hospital was a 377-licensed bed, publicly supported, academic teaching hospital. It was staffed with 200 beds and served a medically indigent population. The hospital had an annual ED census of $\sim 54,000$ visits and admitted $\sim 15,000$ patients per year. Fewer than $5 \%$ of patients have private insurance; the remainder were uninsured or have Medicaid ("Medi-Cal" in California). All interviews were conducted within patient rooms after triage and a rapid medical screening examination.

\section{Study population}

A convenience sample of 245 patients were selected by approaching those either waiting to be seen or pending reevaluation by their care provider. The study excluded those younger than 18 years of age or who did not speak either English or Spanish, and those who were unresponsive or deemed to be in distress. Informed consent was obtained from all respondents.

\section{Assessment}

Measures and outcomes. To assess barriers to the RTH, participants were asked face-to-face through an anonymous, structured questionnaire whether they would desire assistance relating to seven domains of socioeconomic determinants of health: health care, housing security, food security, physical security, financial security, family care, and the community environment. These seven domains were chosen based on published social determinants of health. ${ }^{11,12}$

The domains were further subdivided into 36 issues: health insurance, primary care, specialty care, counseling, 
medical debt, access to rehabilitation or detox facilities, transportation to and from medical facilities, medication storage, housing conditions, obtaining or keeping housing, issues with a landlord, paying for utility bills, foreclosure, food security, locations to purchase healthy foods, personal safety, family violence, neighborhood violence, financial concerns, employment concerns, disability benefits, public benefits, English classes, adult literacy programs, financial planning, debt relief, youth programs, educational issues, family legal concerns, elder care, child care, pet care, criminal justice, immigration, and community improvement. Participants were asked to select the single most pressing area of concern at the time from among the 36 issues.

The questionnaire also assessed demographic characteristics, including age, gender, zip code, household size, citizenship status, and type of health insurance. There was a question regarding the need for legal services within the last year. Finally, the questionnaire assessed self-reported proxies of socioeconomic status including literacy, income, level of education, employment status, and health insurance status.

The questionnaire was pilot tested on patients and consequent revisions made before adopting the final version. For data collection, the questionnaire was administered by one female, native Spanish-speaking research assistant volunteer trained by the ED Research Director in research interviewing technique and who had no previous relationship to study subjects before study commencement. The research assistant explained the intent of the study and her interest in exploring social determinants of health among this population. She read questionnaire items to the patients and marked their responses on the form. No other persons were present with subjects during questionnaire completion.

Questionnaires were generally completed within $15 \mathrm{~min}$. All questionnaires were completed in full. No audio or visual recordings were made, and no field notes were kept. Data saturation techniques were not utilized. No repeat interviews were performed. Participants did not provide feedback on the findings.

Statistical analysis

Questionnaires were collected on paper and managed using REDCap electronic data capture tools hosted at Olive View-UCLA Medical Center. Data entry was performed by the research assistant. Data were then exported into Stata version 10 for analysis (College Station, TX). The data were analyzed using Stata and descriptive statistics were generated including frequencies and percentages for categorical variables. Univariate analyses were also performed to evaluate associations between certain demographic characteristics and any of the 36 barriers to the RTH.

Institutional Review Board approval was obtained from the Olive View-UCLA Education and Research Institute.

\section{Results}

\section{Demographics}

Of 245 potential participants approached, 200 participated in the survey. The majority of respondents were women $(61 \%, 122 / 199)$; mean age was 45 years (standard deviation $[\mathrm{SD}]=15$ years). Levels of English ability and literacy were low; 65\% (128/196) endorsed Spanish as their primary language; 55\% (108/195) self-identified as being literate in English; and 7\% $(13 / 195)$ responded as being nonliterate in their primary language. Similarly, levels of formal education were low. Only slightly more than half $(53 \%, 105 / 199)$ of respondents had completed a high school level of education.

The questionnaire identified high levels of poverty, with $72.6 \%(135 / 186)$ of respondents reporting a household income $<\$ 20,000 /$ year, with a mean household size of 3.2 individuals $(\mathrm{SD}=1.9)$. Only $12.5 \%(25 /$ 198) of respondents were engaged in full-time, yearround work. More than one-third respondents $(36.5 \%, 70 / 196)$ were undocumented. When asked to describe their health insurance status, 40\% (80/199) responded "no insurance," 36\% (71/99) endorsed either Midicare or full-scope Medi-Cal, 14\% (28/199) stated "emergency Medi-Cal," and 9\% (18/99) endorsed "county coverage" (e.g., sliding scale; Table 1).

\section{Barriers to the RTH}

Among study participants, the vast majority indicated desire for assistance with health care-related services, including assistance seeking specialty care $(91 \%, 181 /$ $199)$, primary care $(88 \%, 175 / 200)$, and health insurance $(86 \%, 172 / 200)$. Although health care was the most frequently cited area of concern, there was also a high prevalence of concern with many determinants of health, including food, employment, and housing insecurity; the community environment; transportation; and medical debt (Table 2).

When asked what was the single most pressing issue they faced at the time of the interview, participants most frequently cited health insurance $(30 \%, 59 / 196)$ followed by concerns regarding immigration (12\%, $23 / 196)$ and primary care $(9 \%, 18 / 196$; Table 3$)$. Chi- 
Table 1. Demographic Characteristics

\begin{tabular}{|c|c|}
\hline \multirow{2}{*}{\multicolumn{2}{|c|}{$\begin{array}{l}\text { Age (years), mean (SD) } \\
\text { Gender (\%) }\end{array}$}} \\
\hline & \\
\hline Male & 39 \\
\hline Female & 61 \\
\hline Occupants per household (mean) & 3.2 \\
\hline \multicolumn{2}{|l|}{ Citizenship status (\%) } \\
\hline U.S. citizen & 39 \\
\hline Undocumented & 36 \\
\hline Legal permanent resident & 16 \\
\hline Other (visa, DACA, temporary protected status, asylee/refugee) & 9 \\
\hline \multicolumn{2}{|l|}{ Health insurance status (\%) } \\
\hline No insurance & 40 \\
\hline Medicaid ("Medi-Cal")/Medicare & 36 \\
\hline Emergency Medi-Cal & 14 \\
\hline $\begin{array}{l}\text { Other (county coverage, private, Covered California Insurance } \\
\text { Exchange) }\end{array}$ & 11 \\
\hline \multicolumn{2}{|l|}{ Education level (\%) } \\
\hline Less than high school & 47 \\
\hline Completed high school & 20 \\
\hline Some college & 16 \\
\hline Completed college & 17 \\
\hline \multicolumn{2}{|l|}{ Employment status (\%) } \\
\hline Unemployed & 21 \\
\hline Full-time, year round & 13 \\
\hline Disabled & 12 \\
\hline Retired & 5 \\
\hline Other (seasonal, homemaker, part-time) & 49 \\
\hline \multicolumn{2}{|l|}{ Primary language (\%) } \\
\hline Spanish & 65 \\
\hline English & 28 \\
\hline Other & 7 \\
\hline English literacy (\%) & 55 \\
\hline Literacy in native language & 93 \\
\hline \multicolumn{2}{|l|}{ Annual household income (\%) } \\
\hline$<\$ 10,000$ & 42 \\
\hline$\$ 10,000-\$ 19,999$ & 30 \\
\hline $20,000-\$ 49,999$ & 25 \\
\hline$\$ 50,000-\$ 99,999$ & 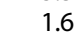 \\
\hline$\geq \$ 100,000$ & 0.5 \\
\hline
\end{tabular}

DACA, Deferred Action for Childhood Arrivals; SD, standard deviation.

square analysis between demographic characteristics and the prevalence of endorsed need suggest those who self-identified as being undocumented were significantly more likely to endorse health insurance as their most important need $(p=0.04)$.

\section{Discussion}

The results of this study demonstrate that, shortly after the implementation of the ACA, barriers to both health and health care persisted among patients of a safety-net health institution. There was high level of demand for assistance in obtaining health insurance, primary care, and specialty care, with almost $50 \%$ of the participants endorsing these issues as their most important need at the time of the interview. Concerns regarding access to health care were especially marked among those who self-identified as undocumented. Furthermore, the study demonstrates vulnerability among this patient population with high rates of poverty, un-
Table 2. Endorsed Need in Addressing Barriers to Health

\begin{tabular}{lc}
\hline Barriers to health & Yes (\%) \\
\hline Specialty care & 91.0 \\
Primary care & 87.5 \\
Health insurance & 86.0 \\
Medical debt & 76.9 \\
Place to buy healthy food & 70.5 \\
Transport to health care facilities & 69.0 \\
Counseling & 68.0 \\
Community improvement & 66.8 \\
Keeping housing & 63.8 \\
Financial concerns & 60.5 \\
Employment concerns & 60.5 \\
Public benefits & 60.5 \\
Paying for utility bills & 59.3 \\
English classes & 57.8 \\
Disability benefits & 55.8 \\
Youth programs & 55.3 \\
Neighborhood violence & 54.3 \\
Immigration & 54.3 \\
Food security & 53.8 \\
Financial planning & 51.5 \\
Housing conditions & 51.3 \\
Obtaining housing & 50.0 \\
Rehab/Detox & 48.0 \\
Debt relief & 47.7 \\
Educational issues & 47.7 \\
Medication storage & 47.0 \\
Elder care & 43.0 \\
Child care & 43.0 \\
Issues with landlord & 41.7 \\
Family legal concerns & 39.7 \\
Family violence & 39.2 \\
Adult literacy programs & 38.7 \\
Criminal justice & 38.5 \\
Personal safety & 37.5 \\
Foreclosure & 33.7 \\
Pets & 31.5 \\
\hline
\end{tabular}

employment, housing insecurity, and illiteracy. ${ }^{13}$ As an example, $72.6 \%$ of the study population reported an annual household income $<\$ 20,000$ dollars, in comparison with median household income of $\$ 56,000$ for Los Angeles County and $\$ 53,000$ nationally from 2009 to $2013 .^{14}$ Similarly, $36.5 \%$ of participants self-reported as being undocumented, and undocumented individuals are estimated to make up $10 \%$ of the population in Los Angeles County and $\sim 4 \%$ of the national population. ${ }^{15}$

Although this study was not designed to fully delineate the persistent barriers to health care shortly after

\section{Table 3. Most Important Expressed Area of Need}

\begin{tabular}{lr}
\hline Area of need & $\%$ \\
\hline Access to health insurance & 30.1 \\
Immigration assistance & 11.7 \\
Access to primary care & 9.2 \\
Housing & 4.6 \\
Access to specialty care & 0.7 \\
Disability benefits & 0.6 \\
Medical debt & 0.4 \\
Other & 31.8 \\
\hline
\end{tabular}


the ACA implementation, the data point toward a multifactorial explanation. Our results can be partially explained by the exclusion of undocumented individuals from the ACA. Although the $35 \%$ rate of undocumented observed in this study is not representative of the broader national picture, it is estimated that there are $>12$ million undocumented individuals residing within the United States. ${ }^{12}$ Exclusion from health insurance contributes to increased dependence on the ED for medical care, a lack of preventative services, delayed management of illness, and the "cycle of preventable hospitalizations." 16 Although this decision has been subject to controversy and debate, it is inconsistent with a value system that recognizes the RTH.

The conflict of dual loyalty faced by practitioners who aim to serve patients equally but work as a part of a health system with structural (including legal) barriers to health care and health has been previously described and is cited as a common element for the violation of the RTH in both "open" and "repressive" societies. ${ }^{10}$ Moving forward, efforts to expand health insurance coverage to the undocumented should be considered to overcome this barrier. Similarly, $\sim 4$ million people are excluded because of their state's decision not to expand Medicaid as a part of the ACA, including $\sim 3$ million in Texas and Florida alone.

Furthermore, our data demonstrate significant barriers to health and health care access even for those populations not explicitly excluded from the ACA. Likely contributing to this patient population's inability to actualize their access to health care are social and economic factors such as low levels of education, lack of transportation, limited English proficiency, poverty, and employment insecurity. These barriers disproportionately affect the underserved and pose significant barriers to health care. Sociologists use the term "structural vulnerability" to describe "a positionality that imposes physical/emotional suffering on specific population groups and individuals in patterned ways" that is borne out of "class-based economic exploitation and cultural, gender/sexual, and racialized discrimination." ${ }^{10}$ Just as natural disasters are far from random, disproportionately affecting those with housing and economic insecurity, medical emergencies often disproportionately affect populations affected by structural vulnerability. Health care systems seeking to fulfill the RTH among the poor must take these factors into account. Given the ED's unique role in the social welfare system, it may serve as the ideal venue to both screen for and address social and economic barriers to health care, in cooperation with community-based organizations.

Third, this study suggests a need to ensure funding and quantity of services be afforded to populations historically served by the safety-net health system to overcome residual barriers to health care. A large percentage of the insured study cohort endorsed concerns regarding access to primary and specialty care, suggesting a lack of resources to serve the expanded number of insured patients. This hypothesis is supported by national data demonstrating a lack of primary care doctors to serve the expanding population of insured individuals and the cutbacks in intended funding to community clinics as a part of the ACA. ${ }^{17}$ As a result, the theoretical opportunity for health care diverges from the actual access to health care for large segments of the populations served at safety-net health facilities. Given this discrepancy, caution must be taken in withdrawing funding from the traditional safety-net system and hospitals serving a disproportionate share of uninsured and underinsured patients (i.e., "DSH" hospitals).

Finally, this study demonstrates how the health and human rights framework may be applied as tool for analysis in the ED setting. Although clinical outcomes, cost effectiveness, and patient satisfaction have become well-recognized frameworks for assessing ED interventions, the health and human rights framework is arguably unique from other health-related frameworks (e.g., patients' rights, consumer rights) in that it is grounded in the concept of health equity. Alternative frameworks of analysis can have divergent ramifications in the analysis of a singular reality. As an example, during the HIV/AIDS pandemic of the 1990s, cost-effective analysis that held funding and drug prices to be fixed determined that it would be cost-effective to defer treatment of those already inflicted with HIV in favor of preventative interventions. A health and human rights framework applied to the same reality, in confluence with the rise of generic antiretroviral drugs and grassroots activism, exponentially increased global access to life-saving drugs. ${ }^{18}$

\section{Limitations}

This study has several limitations. The study population was a convenience sample of patients in the ED who were deemed not to be in acute distress. Furthermore, the study was conducted entirely at a single safety-net ED, and, therefore, is not representative of the national population. All demographic characteristics were self-reported and may deviate from actual 
characteristics. Similarly, self-reported barriers to health and prioritizations maybe biased toward health care given the context of the questionnaire being administered in the ED. Finally, this study was performed shortly after ACA implementation. In the interim, the ACA has improved access to health care and health outcomes for patients covered by its provisions. ${ }^{19}$ Many of our ED's previously uninsured patients have benefited from the ACA; rates of uninsured decreased in Los Angeles County from $28.5 \%$ in $2011^{20}$ to $\sim 10.5 \%$ in $2016,{ }^{21}$ and nationally from $17.4 \%$ to $10.9 \%{ }^{22}$

Nonetheless, barriers to health care and health persist. $^{23}$ Thirty-six percent of this study's subjects were undocumented immigrants, unable to benefit directly from Medicaid expansion or the health insurance exchanges. High and increasing health insurance premiums for plans offered on the exchanges or through other private entities further limit participation; between 2008 and 2018, premiums for family coverage increased to $55 \%$, and employees' share by $65 \%{ }^{24}$ Even among those who have recently acquired health insurance, narrow networks and lack of specialty providers willing to except Medicaid rates limit specialty care access, ${ }^{25,26}$ which was a concern of our $91 \%$ of our subjects. However, the ACA has accelerated emphasis on addressing social determinants of health ${ }^{27,28}$ by connecting patients to community resources, food/nutrition, housing, education, employment, and so on. Such focus "upstream" 29 benefits even those ineligible for ACA-related health insurance, ${ }^{30}$ including our ED population, ${ }^{31}$ among whom such social determinants represented substantial concerns.

\section{Conclusion}

Although the ACA has made notable strides in extending the provision of health insurance in its early stages, this study suggests that barriers to the RTH among marginalized patient populations persist. These barriers can be further divided into barriers to health care and barriers to health. Barriers to health care include the explicit exclusion of individuals from coverage (e.g., the undocumented), structural barriers to the realization of health care services, and underfunding of health institutions to serve the newly insured poor. Despite passage of the ACA barriers to a holistic definition of health also persist in this study population, highlighting the need for collaboration between health providers, patients, and advocates to address structural factors that have significant bearing on health outcomes and equity. Finally, this study demonstrates how the health and human rights framework maybe used as a tool to promote health and health equity among marginalized patient populations.

\section{Acknowledgment}

The authors thank the staff of Neighborhood Legal Services, Pacoima, CA for their contributions to questionnaire design.

\section{Author Disclosure Statement}

No competing financial interests exist.

\section{References}

1. Congressional Budget Office. Updated Estimates for the Insurance Coverage Provisions of the Affordable Care Act. Washington, DC: Congressional Budget Office, 2012

2. Carman KG, Eibner C, Paddock SM. Trends in health insurance enrollment, 2013-15. Health Aff (Millwood). 2015;34:1044-1048.

3. Begley C, Deshmukh A, Eschbach K, et al. Health insurance coverage in the Houston-Galveston area under the patient protection and Affordable Care Act. Tex Med. 2012;108:e1.

4. Adepoju O, Preston MA, Gonzales G. Health care disparities in the post-Affordable Care Act Era. Am J Public Health. 2015;105(Suppl. 5): S665-S667.

5. Colgrove J. The McKeown thesis: a historical controversy and its enduring influence. Am J Public Health. 2002;92:725-729.

6. Gordon JA. The Hospital Emergency Department as a Social Welfare Institution. Ann Emerg Med. 1999;33:321-325.

7. World Health Organization. Constitution of WHO: Principles. Available at www.who.int/about/mission/en Accessed February 21, 2019.

8. Castañeda $\mathrm{H}$, Holmes SM, Madrigal DS, et al. Immigration as a social determinant of health. Annu Rev Public Health. 2015;36:375-392.

9. World Health Organization. Human rights and health: Key facts. Available at www.who.int/news-room/fact-sheets/detail/human-rights-and-health Accessed February 21, 2019.

10. Cohen J, Ezer T. Human rights in patient care: a theoretical and practical framework. Health Hum Rights. 2013;15:2-19.

11. Braveman P, Gottleib L. The social determinants of health: it's time to consider the causes of the causes. Public Health Rep. 2014;129(Suppl. 2): 19-31.

12. Currie C, Zanotti C, Morgan A, et al., eds. Social determinants of health and well-being among young people. Health Behaviour in School-aged Children (HBSC) study: international report from the 2009/2010 survey. Copenhagen, WHO Regional Office for Europe, 2012 (Health Policy for Children and Adolescents, No. 6).

13. Quesada J, Hart LK, Bourgois P. Structural vulnerability and health: Latino Migrant Laborers in the United States. Med Anthropol. 2011;30:339-362.

14. U.S. Census. Available at www.census.gov/quickfacts/table/PST045215/ 06037 Accessed July 7, 2015.

15. Passel JS, Cohn, D. Unauthorized immigrant population stable for half a decade. Pew Research Center, 2015. Available at www.pewresearch.org/ fact-tank/2016/09/21/unauthorized-immigrant-population-stable-forhalf-a-decade Accessed March 15, 2017.

16. Wallace SP, Torres J, Sadeh-Nobari T, et al. Undocumented immigrants and health care reform. UCLA Center for Health Policy Research report to The Commonwealth Fund. Available at http://healthpolicy.ucla.edu/ publications/Documents/PDF/undocumentedreport-aug2013.pdf Accessed July 18, 2018.

17. Petterson SM, Liaw WR, Phillips RL, Jr., et al. Projecting US primary care physician workforce needs: 2010-2025. Ann Fam Med. 2012;10:503-509.

18. Novogrodsky N. The duty of treatment: human rights and the HIV/AIDS pandemic. Yale Hum Rights Dev J. 2009;12:1-61.

19. Glied SA, Ma S, Borja A. Commonwealth fund report: effect of the Affordable Care Act on health care access. Available at www .commonwealthfund.org/publications/issue-briefs/2017/may/effect-acahealth-care-access Accessed August 27, 2018. 
20. Los Angeles County Department of Public Health. LA Health: Recent Trends in Health Insurance Coverage. April 2017. Available at http:// publichealth.lacounty.gov/docs/LaHealth_RecentTrendsInHealthInsurance Coverage_yr2017.pdf Accessed February 22, 2019.

21. U.S. Census. Available at www.census.gov/quickfacts/fact/table/ losangelescountycalifornia/BZA010216 Accessed February 22, 2019.

22. Henry J. Kaiser Family Foundation. Key Facts about the Uninsured Population. Available at www.kff.org/uninsured/fact-sheet/key-facts-aboutthe-uninsured-population Accessed February 22, 2019.

23. McMorrow S, Polsky D. Penn Leonard Davis Institute of Health Economics report: insurance coverage and access to care under the Affordable Care Act. Available at https://ldi.upenn.edu/brief/insurance-coverage-andaccess-care-under-affordable-care-act Accessed August 30, 2018.

24. Kaiser Family Foundation. 2018 Employer Health Benefits Survey. Available at www.kff.org/health-costs/report/2018-employer-health-benefitssurvey Accessed February 23, 2019.

25. Sommers BD. Health care reform's unfinished work-remaining barriers to coverage and access. N Engl J Med. 2015;373:2395-2397.

26. Allen EM, Call KT, Beebe TJ, et al. Barriers to care and healthcare utilization among the publicly insured. Med Care. 2017;55:207-214.

27. Chaiyachati KH, Grande DT, Aysola J. Health systems tackling social determinants of health: promises, pitfalls, and opportunities of current policies. Am J Manag Care. 2016;22:e393-e394.

28. HealthyPeople 2020. Social determinants of health. Available at www.healthypeople.gov/2020/topics-objectives/topic/socialdeterminants-of-health Accessed February 23, 2019.

29. Manchanda R. The Upstream Doctors: Medical Innovators Track Sickness to Its Source. New York: TED Conference, LLC, 2013.

30. National Association of Community Health Centers. Powering Healthy Communities: Community Health Centers Address the Social Determinants of Health. August 2012 Issue Brief. Available at www.nachc.org/wp-content/ uploads/2016/07/SDH_Brief_2012.pdf Accessed February 22, 2019.

31. Los Angeles County Department of Health Services. Community Health and Integrated Programs. Available at http://dhs.lacounty.gov/wps/ portal/dhs/!ut/p/b1/04_SjzSxMDlyMTEzMtKP0I_KSyzLTE8syczPS8wB8a PM4t0MDAzc_Z2Cjdzd_Q0MHEMtjPz9PD2NLVwMgQoikRVYmPo5GT gamJj6W3iYGDqbGhDSH64fhaoE3QRTQgoMoAoMcABHA30_j_ zcVP3cqBxLzywTRQCromAV/dl4/d5/L2dJQSEvUUt3QS80SmtFL1o2XOY wMDBHT0JTMkdHTzAwQVU4Mk9OSUkzOFIw Accessed February 22, 2019.

Cite this article as: Samra S, Pelayo E, Richman M, McCollough $M$, Taira BR (2019) Barriers to the right to health among patients of a public emergency department after implementation of the Affordable Care Act, Health Equity 3:1, 186-192, DOI: 10.1089/ heq.2018.0071.

\section{Publish in Health Equity}
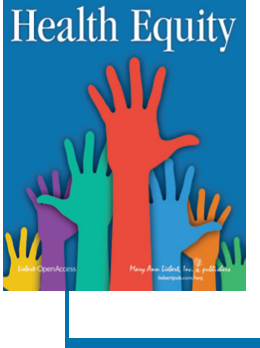

- Immediate, unrestricted online access

- Rigorous peer review

- Compliance with open access mandates

- Authors retain copyright

- Highly indexed

- Targeted email marketing

liebertpub.com/heq 